\title{
Analysis on the design of children's puzzle toys
}

\author{
Wang Tengfei ${ }^{1, \text { a }}$ \\ ${ }^{1}$ Jiangxi college of foreign studies,NanChang,330099, China \\ àWangTengfei@yeah.net
}

Keywords: Children's game; Make-up game; Puzzle game; Design and development; System implementation.

\begin{abstract}
Twenty-first Centuries is a blend of information and technology era, the child is the future of the motherland, the hope of parents. Their physical and mental health and mental development is increasingly valued, especially in school age, this is an important period of rapid growth is not to relax. The infant toys as an important product development of infant children's full potential, in the industrial design system gradually perfect, because the particularity of users and features, and children's toys product design, product design and other infant and other stages are very different. Our country toy production and consumption power, how to design suitable for preschool children in this stage has China characteristics and how to adapt to the international market of toy products, is an important issue facing the field of toys design in china. This paper uses interdisciplinary research methods, using the theories of child psychology, methodology of product design, color psychology, bionics, material science, semiotics, and other product design, combined with the investigation, and a large number of case studies, thinking of research and analysis, the comprehensive use of induction and deduction and for the preschool children educational toys are designed. Children's educational toys quality is uneven, there is little innovation in the design, while the lack of internal culture products. This paper discusses the definition, development, classification and functions of children's educational toys, and further analyzes the relationship between children's educational toys and the healthy growth of children's physical and mental health. According to the psychological needs of the children, the article clarifies the basic elements of children's educational toys design, and puts forward the design of educational toys for children should follow the principle of design, they are security and user, fun, educational and interactive. In this paper, we take the puzzle game as an example to illustrate.
\end{abstract}

\section{Introduction}

Refers to the children's toys for children games use items. Toys are the backbone of the psychological process of children's imagination, thinking and other psychological process. Children's toys to develop athletic ability, training consciousness, stimulate imagination, arouse curiosity, physical and mental development of children provided material conditions. A good toy for children is to guide a child growth partners. Preschool age is a period of great changes in the physiology and psychology of early childhood. As long as it is possible, they play all day. Although children under different cultural backgrounds play in different ways, but in the process of playing shows around the adult activity to imitate, and these activities can provide many of the things and people interaction for children the opportunity. Children in this period have the characteristics of emotional instability, need to carry out a lot of social study and practice under the guidance of the. The more things a child sees before the school age, the more developed the synapse. The color, shape, movement and other characteristics of these things are very educational to preschool children. With the improvement of our living standards, parents of children's intelligence development of the gradual attention, intelligence toys are popular with parents[1], children's educational toys consumption is also getting higher and higher. Now, many new couples in our country can only have a child, they put their hopes on the children, hope that children can receive a good education. According to the survey of 380 million children in our country, the number of only child is up to 129 million. The global toy sales of up to $\$ 83$ billion 300 million in 2010, 4.7\% more than in previous year's Rapid development of the 
Asian market, an average increase of 9.2\% over the previous year, Asia has become the world's second largest toy market. At the same time, China's toy exports reached 10 billion 80 million U.S. dollars, increased by $29.4 \%$ over last year. To sum up, children's educational toys have a broad consumer market. The rapid development of children's educational toys market, leading to the form of Chinese children's toys in a single, no innovation, and the existing children's toys can not meet the needs of children and parents. China's many children's educational toys copied foreign similar products, which have restricted the development of China's educational toys, so that the quality of children's educational toys can not be guaranteed, the design of the lack of innovation. At the same time, children's educational toys can make children become more intelligent and have an important role in the development of children's imagination and creativity. At the same time educational toys to have a strong intelligence and entertainment. For example, educational toys to stimulate the function, bright color, smooth lines of educational toys, which contribute to the development of children's vision; makes all sorts of animal sounds or to simulate the sounds of nature of educational toys, they can stimulate the children's auditory development; to color ball, there is some help for children's touch the development of. Therefore, different kinds of children's educational toys can help children to understand the things around, but also to promote the development of their sensory organs, so that they can understand the unknown things through the senses[2].

\section{An overview of preschool children's educational toys}

Definition of preschool children's educational toys. Children's educational toys for children to play in the process of developing intelligence. In 1983, Gardiner Howard, a world famous educational psychologist, proposed the theory of multiple intelligences. According to the theory of multiple intelligence, human intelligence is the ability to solve the problems encountered in the specific social value standards. According to this theory, our intelligence is not just one kind of ability, but we have many abilities at the same time. Gardiner believes that people have eight intelligences, they exist between each other, but they are independent of each other. Eight intelligent are logical intelligence, linguistic intelligence, spatial intelligence, musical intelligence, sports intelligence, intrapersonal ability, interpersonal intelligence, natural intelligence exploration. Each person has a number of intelligence, the difference is that each person has the strength of intelligence, different types, resulting in individual differences between people. It is generally believed that human beings have five abilities in intelligence, which are attention, observation, thinking, memory and imagination. To sum up, the puzzle is to help children to develop their ability to develop a certain intellectual or a variety of intellectual toys. Children's educational toys can make children become more intelligent and have an important role in the development of children's imagination and creativity. At the same time, the educational toy should have a very strong intelligence and entertainment. For example, educational toys to stimulate the function, bright color, smooth lines of educational toys, which contribute to the development of children's vision; makes all sorts of animal sounds or to simulate the sounds of nature of educational toys, they can stimulate the children's auditory development; to color ball, there is some help for children's touch the development of. Therefore, different kinds of children's educational toys can help children to understand the things around, but also to promote the development of their sensory organs, so that they can understand the unknown things through the senses. Puzzle toys can also promote the development of children's physical coordination, such as children with the building blocks out of the imagination of graphics, children in addition to imagination, but also the need for their body with. Children's educational toys through training, they can quickly use and coordination of related actions, and their ability of hand eye coordination can be improved; to promote the development of children's interpersonal intelligence, children in common with others Wan Yizhi toys, they need to interact with peers, even when children quarrel, the cultivation of these are help children with team cooperation ability, in the event of conflict, they can be a very good understanding of their own, have certain benefits on the training of children's interpersonal intelligence. In the whole process, children need to communicate with people, can 
exercise their language ability; through the quarrel with others, can effectively release their negative emotions; by playing the toy, can promote the harmonious development of their body function[3].

Cognitive intelligence toys. Self development is an important part of the socialization of the baby, and understanding of the external things can make the baby more directly into the social role. Many studies show that the things outside the cognition, even the baby's self cognition mostly interact with the external environment and the toys become AIDS this important cognitive process, such as the baby through a small mirror understanding of facial features, through the cognitive understanding of various animal cards.

EQ enlightening puzzle toys. Einstein said: "the success of intelligence depends greatly on the character of the great. "For children outside the intelligence of the training, the baby's life will have a significant impact. Emotional intelligence first toy through the baby familiar, cognitive surrounding life style, including dolls, plush toys, scene set, such as the design of the environment around the scene of toys, such as the role playing tools such as health care tools. EQ toys for children to express emotions and enlightenment experience of adults and life, but also have the opportunity to understand and absorb the experience, improve the baby's self-confidence, independence, curiosity, emotional control, sense of rules, empathy, social adaptation ability and peer cooperation and communication ability.

\section{The design principles of children's educational toys}

Security principle. The fancy toy safety is reflected in the process of children's normal use of toys, without any harm from toys, wrong operation even in the unconscious, can also damage to a minimum, so as to ensure the safety of children. Now, every couple has only one child, the child's parents hope and sustenance, their health and safety is attracting attention because of all the members of the family, some children's educational toys structure design is not reasonable to hurt children. Therefore, the safety of children's educational toys for children and parents is very important. Lively is the nature of children, and children can not accurately control the body, sensory systems in their development is not very mature, and there is no awareness of self-protection, they will face many security problems. Children's educational toys may exist many security problems, such as cutting, pinching and other security issues. Therefore, designers in the design of children's educational toys, should choose environmentally friendly, durable materials, designed for children's health benefits of children's toys. The external structure of children's toys must not have sharp corners, using the overall structure design, reduce the toy surface hole, eye, and ensure the firmness between the parts, avoid parts fall off, let the children accidentally swallowed. Children's educational toys accessories size should not be too small, and no food or food with the smell of appearance design of toys, so it can effectively reduce the probability of children's eating or mistakenly insert opening. Designers in the design of children's toys, the operation of the toy to make some restrictions, to avoid the child's mistake to bring harm to children. For example, the uses of physical structure constraints, but also to provide users with instructions, which can help parents correctly guide the use of toys for children[4]. Human machine principle. Children's educational toys, performance in the toy is simple, easy to use, and to be suitable for children's operating habits. The size and volume of toys for children to meet the children's body index, to reflect the man-machine relationship between children and toys, children's toys designed to sell the comfort, let the children enjoy the fun toys, rather than on their bodies. In the design of children's products, designers should take full account of the characteristics of children's physical and mental development, according to the characteristics of children's design in accordance with the nature of children's products. Because the child's mind and patience is not mature, for children's toys structure complex, children often daunting, they will transfer target, looking for their own toys. Interface design of children's toys, must highlight simple, can use simple shapes and more eye-catching colors, and so that children can quickly understand things, to facilitate the identification and memory, children can quickly get new toys. In addition, the use of children's knowledge of the shape and eye-catching colors of the child to produce association, help to improve the imagination and creativity. According to the children's physical growth characteristics, the design 
of children's toys can be designed to "grow" together with the children, children's toys, by adjusting the size of free combination, to achieve the function of the toy diversity, to meet the various needs of children of different ages, this design reflects the design principles of environmental protection and energy saving. A lot of children's toys are to be accompanied by adults and children to play with, in the design of children's toys, to take into account the convenience of adult use, to facilitate interaction between adults and children. Good human communication and communication is a necessary condition for children's toys, toys, toys not only reflect a simple interface, but also to bring joy to children, but also to meet the needs of children's physical.

Interest principle. Children's educational toys interesting performance in the toy affinity, full of vitality and fun and so on. Active, playful, curiosity is the nature of children, they love to imitate, love to find interesting things from different point of view. Children in order to cognitive things, they show active playing habits, this is there a way of understanding the world. Children can not only get pleasure from the entertainment and games, but also promote their development of sports intelligence, and gain more knowledge and life skills. For children with a pleasant and affinity for educational toys, children are very popular. Because children can not focus on one thing for a long time, their self-control is relatively poor, so the toy to highlight its interesting point, so as to attract the attention of children, to stimulate their interest in the role of. The observation, imagination, creativity, and the development of this kind of toy, promote their harmonious development. This kind of children's educational toys can make children find happiness, accompany children to grow up, let the children knowledge and friendship. Exaggerated, cartoon style can increase the interest of children's educational toys. Cartoon style is used by many designers, because it is very interesting, children like them very much. According to the survey, exaggerated and anthropomorphic cartoons popular with children, children very intimate feeling of animated cartoon image, for example, grey wolf and other Beaming with Joy. Frog company for children to design a children's mouse, mouse model design, show in front of the child like a real mouse, cute mouse modeling, so that children have a sense of intimacy, to bring a lot of fun. In the design of children's products, but also in the operation of the increase in interest points, so that children can be fun when the operation, the heart is satisfied[5].

The principle of intelligence. Children's educational toys puzzle performance in the development of children's intelligence, creativity and other potential. The main function of the toy is to provide for children's entertainment, children are happy to play, at the same time the children get knowledge and life skills. Nowadays, parents pay more and more attention to the development of children's intelligence, with the increase of children's age, the ability of children has been continuously improved. Children have strong imitation ability, ordinary toys can no longer meet the needs of their toys from a simple entertainment to multi functional transformation, the essential functions of learning and education function of children's educational toys, design must put it in the priority. If the designer of children's educational toys can get the user's favorite, and let still get happiness, while helping to the development of intelligence, this kind of children's educational toys will be able to obtain the recognition of parents. Children's educational toys can develop children's intelligence to early, is beneficial to cultivate children's thinking ability and creative ability, but also can promote children's brain development, is conducive to the further development of children's senses and thinking abilities, their curiosity can be met. Children's educational toys to stimulate children's interest in learning, knowledge and life skills. Children playing with toys in the process, the need to cooperate with the body, which can be a good training of children's physical coordination, help children improve their fine action. For example, the structure of toys (model building, etc.), children can be split and combined to promote the development of educational toys, children's imagination and creativity; collocation dress and hair style dolls, children can get a doll dressed, can exercise the child's life skills. Tangram is China traditional folk toys, seven plates can be combined into a variety of specific image, the object image, it can cultivate children with countless changes, observation, imagination, can let the children to establish a connection between real and form. Tangram to stimulate children's creativity, gives them freedom, but also helps to enhance children's patience. 


\section{Summary}

In the design of children's educational toys, to grasp the essence of the design, toys for the game, to bring joy to children, followed by the realization of other functions. In the design, the designer to design the object has good design orientation, through the user's age, understand their physiological and psychological needs, so that the design has very strong pertinence, can better meet the needs of the users. Design products to give people a sense of security, can not cause harm to the human body, and can not give people the psychological burden. Good design products have a good guide, help the development of physical and mental health of children, through the product allows them to form their own ability and better understanding of the objective world.

\section{References}

[1] Yang Hua, Wang Le. Study on the experience design of children's educational toys [J]. packaging engineering. 2011 (14).

[2] Liu Huawei, Yu Min. Innovative design of children's educational toys [J]. Journal of Zhengzhou University of Light Industry (SOCIAL SCIENCE EDITION). 2010 (02).

[3] Liu Zijian, Wang Juan. Research and application of modern children's toy design [J]. the United States and the times (the second half). 2009 (06).

[4] Liu Huawei, Yue Kun. A brief discussion on several elements of children's toys design [J]. art and design (Theory). 2009 (08).

[5] Lu Xiaoqin, Li Zhiying's theory of cognitive development in children's educational toys in the design of packaging engineering using [J]. 2009 (12). 